Original Article

\title{
Effectiveness of planned teaching programme on knowledge regarding pubertal changes among adolescent boys in selected high school of Udupi District
}

\section{Ajith Kumar Shetty ${ }^{1}$, Alphoni P. George ${ }^{1}$, Beena K.J. ${ }^{1}$, Tandra Kabiraj ${ }^{1}$, Blenita Paul ${ }^{1}$, Anil Raj A. ${ }^{2}$ \& Soumya Alex ${ }^{3}$}

${ }^{1}$ P.B.BSC Nursing Students, ${ }^{2}$ Lecturer, Department of Medical Surgical Nursing, ${ }^{3}$ Assistant Lecturer in Department of Fundamentals of Nursing, M anipal college of Nursing, M anipal University, M anipal.

*Corresponding Author : Anil Raj A., Administrative Officer, ICM R-DHR Funded Project, M anipal College of Nursing Manipal, Manipal University, M anipal. M obile : +917411892986 E-mail : anilrajan1987@gmail.com

Received : 01-09-2015

Review Completed : 13-05-2016

Accepted

: 14-05-2016

Keywords : Effectiveness, planned teaching program, pubertal changes, adolescent boys.

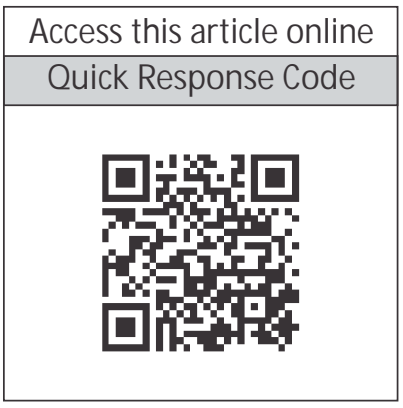

\begin{abstract}
:
Adolescent is a challenging crossroad between childhood and the adulthood. It is considered as vital because of the physical, physiological and psychological changes take place during this period. These changes occur in puberty may bring about a feeling of fear and apprehension in adolescent boys. Proper knowledge and timely guidance and information can enable them to enjoy the adolescent period. Objectives of the study were to assess the knowledge regarding pubertal changes among adolescent boys, by using a structured knowledge questionnaire and evaluate the effectiveness of planned teaching programme. Pre experimental one group pretest post- test design was used among adolescents in selected high school of Udupi District. The study participants (100) were assessed through a questionnaire and selected by purposive sampling. Data shows that mean knowledge score of the group before intervention was $16.96 \pm$ 3.816. After intervention (the planned teaching program), the mean knowledge score was 24.05 \pm 3.036 which indicates the significant difference in mean pre-test and post-test knowledge scores, and paired t-test showed the statistical significance for the effectiveness of planned teaching programme (" $\mathrm{t}$ " $=14.352$ and $\mathrm{P} \varangle 0.05$ ). The study concluded that planned teaching was found to be effective in improving the knowledge regarding pubertal changes among adolescent boys and it would be beneficial to manage the physical and psychological problem related to puberty.
\end{abstract}

\section{Introduction}

Adolescent is a challenging crossroad between childhood and the adulthood. Adolescent is the period between 11 to 19 years. It is considered as vital because of the physical, physiological and psychological changes take place during this period. It is the time that an individual's life when he learns to make choices based on experience, skills and values gathered in this period ${ }^{1}$. Due to lack of proper knowledge regarding pubertal changes, adolescent boys may have increased anxiety, excessive worry, fear, nervousness, restlessness, extreme stress and dreams about future which may lead to many complications such as drug abuse, underage and teenage drinking, drunk driving, smoking, rebellious behaviour, peer pressure, bullying, lying, body issues and mental health issues. They may complain of physical symptoms like muscle tension, headache, stomach ache, fatigue and tremor. Proper and timely guidance and information can enable them to enjoy the adolescent period. Adolescent boys have as many as health issues and concerns as adolescent females. M ost of the adolescent boys get improper information from peer group and media to address their concerns such as puberty and sexuality. The adolescent girls get knowledge about their physiological changes from their mothers but in case of boys, fathers do not get involved in preparing them ${ }^{2}$. Study conducted in Bagalkot, Karnataka, with the objective to evaluate the awareness regarding puberty changes in adolescent age group reported that only $19.80 \%$ of 394 total participants, had correct knowledge regarding secondary sex characteristics during pubertal period ${ }^{3}$. As 
"prevention is better than cure", it is always better to create an awareness regarding pubertal changes among adolescent boys to prevent many physical, psychological as well as social complication among the adolescent boys and help them to lead a happy and productive life in future.

\section{Material and methods}

Pre experimental research method with one group pre-test post-test research design was used for the research study. The population of the study were adolescent boys between the age group of 13 to 15 years. Total 100 participants were selected from selected High school of Udupi District by using purposive sampling. Data were collected from $28^{\text {th }}$ January 2014 to $4^{\text {th }}$ February 2014.

The structured knowledge questionnaire was used to collect the data from the participants and it was developed by the investigators following an extensive literature review. The prepared tool along with the objectives, blue print and criteria check list were given to five experts from various fields to ensure the content validity. Out of 36 questions, 2 questions were discarded as per the disagreement of three validators and 34 questions were finalized for pretest and reliability.

Reliability of the structured knowledge questionnaire was established by split half method among 10 samples and the tool was found to be reliable $(r=0.78)$

Written permission was obtained from the Institutional Ethics Committee (IEC) and from the principal of concerned school before the data collection and the investigators familiarized themselves with the participants and explained the purpose of the study to them. An informed consent and assent were taken from the parents and participants respectively. After giving necessary instructions to the subjects, the baseline information was collected.

Pre-test knowledge level was assessed from 100 adolescent boys by using Structured Knowledge Questionnaire. Time taken for the Pre-test was 30 minutes. On the same day, after the pre-test, Teaching Programme on Pubertal changes among adolescent boys was conducted to the participants. Post-test was conducted on the $8^{\text {th }}$ day after the Planned Teaching Programme using the samestructured knowledge questionnaire.

\section{Results}

\section{Description of sample characteristics}

With regard to sample characteristics out of 100 subjects $65 \%$ in the study were at 14 years of age and $73 \%$ were at $9^{\text {th }}$ standard. Data on religion showed that $77 \%$ of the samples belong to Hindu religion. Regarding the previous knowledge regarding pubertal changes Most of the participants (86\%) have no previous knowledge about pubertal changes. And among $14 \%$ of total participant who got some knowledge from different sources, $11 \%$ got knowledge from text book, $2 \%$ from family and $1 \%$ from internet.

\section{Description of knowledge score}

Percentage distribution of pre-test and post-test knowledge score about pubertal changes among adolescent boys are presented in Table 1 which shows that the most of the boys (73\%) had average knowledge and only $22 \%$ boys had good knowledge before the teaching programme whereas after teaching programme the percentage of adolescent boys with good knowledge increased to $86 \%$.

\section{Effectiveness of planned teaching Program}

$\mathrm{H}_{01}$ : The mean pre-test knowledge scores will be significantly higher than the mean post-test knowledge scores.

The significant difference between the mean pre-test and post -test knowledge scores was computed using the paired t- test and it is presented in table 2 . Here ' $p$ ' value is < 0.05

\section{Discussion}

The objective of the study was to assess the knowledge regarding pubertal changes among adolescent boys, by using a structured knowledge questionnaire. The present study found that among the sample size of 100 adolescent boys, $14 \%$ said that they had knowledge regarding puberty and $86 \%$ participants said that they did not know about 
Table 1: Frequency and percentage distribution of pre-test and post-test knowledge score regarding pubertal changes amongadolescent boys

\begin{tabular}{lcccc}
\hline Knowledge & \multicolumn{2}{c}{ Pre-test score } & \multicolumn{2}{c}{ Post-test score } \\
& Frequency (f) & Percentage (\%) & Frequency (f) & Percentage (\%) \\
\hline Poor (0-10) & 5 & 5 & 0 & 0 \\
Average (11-20) & 73 & 73 & 14 & 14 \\
Good (21-30) & 22 & 22 & 86 & 86 \\
Total & 100 & 100 & 100 & 100 \\
\hline
\end{tabular}

Table 2 : M ean, standard deviation and mean percentage of pre-test and post-test knowledge scores of adolescent boys regarding pubertal changes.

$n=100$

\begin{tabular}{|c|c|c|c|c|c|c|c|c|}
\hline & \multicolumn{3}{|c|}{ Paired differences } & \multicolumn{4}{|c|}{ 95\%confidence interval } & \multirow[b]{2}{*}{ p-value } \\
\hline & Mean & SD & $\begin{array}{c}\text { Mean } \\
\text { percentage }\end{array}$ & Lower & Upper & $\mathbf{t}$ & df & \\
\hline Pre-test & 16.96 & 3.816 & 56.53 & & & & & \\
\hline Post-test & 24.05 & 3.036 & 80.17 & 6.110 & 8.070 & 14.352 & 99 & $0.001 *$ \\
\hline
\end{tabular}

puberty. In the present study, overall knowledge improvement was found after planned teaching programme. A similar study was conducted in Mumbai slum area with the objective to assess the knowledge of adolescent boys regarding physical, emotional and psychological changes occurring during puberty. Among sample size of 256 adolescent boys, $58.98 \%$ had some knowledge and $41.02 \%$ participants had no knowledge regarding puberty ${ }^{4}$.

\section{Conclusion}

Pubertal changes among adolescents are an important stage in everybody's life. Adolescents undergo significant physical, emotional and psychological changes during their pubertal development. These changes contribute to their future development. Educating adolescents at an early age

\section{Reference}

1. Marlin J, Hockenberry. Wong's essentials of paediatric nursing. $8^{\text {th }} \mathrm{ed}$. St.Lovis: Saunder Elsevier: 2009.

2. Wikimedia foundation Inc. 2013: Available from en.wikipedia.org

3. Dorle AS, Hiremath LD, Mannapur BS, Ghattargi CH. Awareness regarding puberty changes in secondary school children of Bagalkot Karnataka- A cross sectional study. J of Clin and Dig Re Study. 2010 Oct: 4:3016-3019.

4. Devidas T, Sekhar KS, Kembhavi RS. Perception of adolescent boys regarding pubertal changes (physical, emotional and psychological) from urban slum area of M umbai. Ind J of Pub Hel Re and Develop. 2011;2(2): 42-46.

5. Bhandari U M etal. A study to evaluate the effectiveness of planned teaching programme on knowledge of mothers on prevention of hypothermia among newborns in selected hospitals of Belgaum, Karnataka. India. Jaypee Journals, 2010 about their expected development decreases the possible anxiety which is associated with this period of life and also helps adolescents make better choices with regards to their sexuality ${ }^{2}$. After the administration of planned teaching program, the post-test measures showed that there was an overall gain in knowledge score, and significant increase in knowledge in the areas. Indeed it can be concluded that the planned teaching programme is effective strategy to improve the knowledge of the adolescent boys and it is helpful to include such kind of teaching programs for the boys who are undergoing the pubertal changes. The knowledge regarding pubertal changes is vital to face the physical, physiological and emotional changes during adolescence period among boys and teaching program facilitates to acquire the knowledge among adolescent boys. 